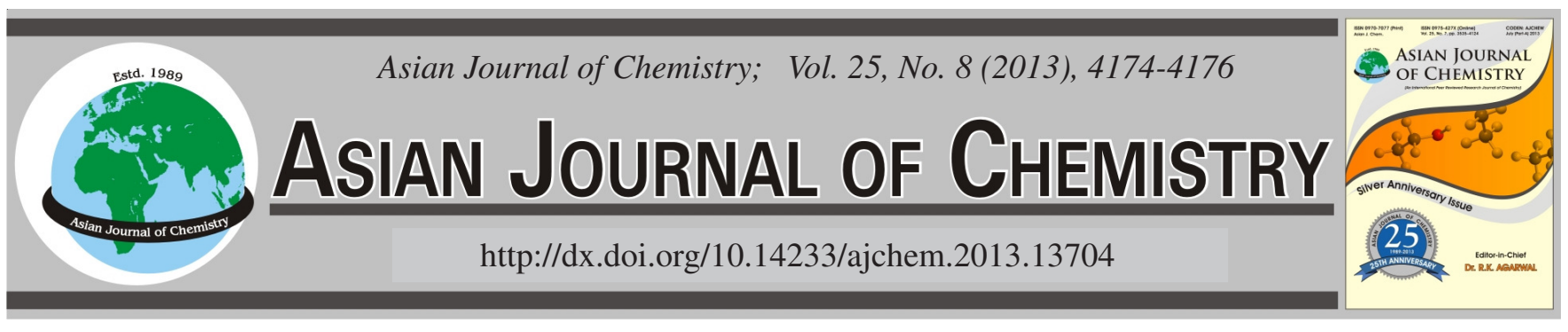

\title{
Evaluation of Acetylcholine Esterase and Protease Inhibitory Potential of Sonchus oleraceus, Melia azedarach and Citrus sinensis
}

Shafiq-ur-Rehman ${ }^{1}$, Durre Shahwar ${ }^{1, *}$, Muhammad Asam Raza $^{2}$, Afifa Saeed $^{1}$, Faiza Ilyas $^{1}$ and Saba Qaiser ${ }^{1}$

${ }^{1}$ Research Lab II, Department of Chemistry, Government College University, Lahore, Pakistan

${ }^{2}$ Department of Chemistry, Hafiz Hayat Campus, University of Gujrat, Gujrat, Pakistan

*Corresponding author: Fax: +92 42 9213341; Tel: +92 429213340 Ext. 266; E-mail: drdshahwar@yahoo.com

(Received: 9 March 2012;

Accepted: 4 February 2013)

AJC-12921

\begin{abstract}
Sonchus oleraceus (Family: Asteraceae), Melia azedarach (Family: Meleaceae) and Citrus sinensis (Family: Rutaceae) were extracted in methanol and partitioned with hexane, ethyl acetate and $n$-butanol successively. Acetylcholine esterase (AChE) and protease activities were carried out by reported methods. Ethyl acetate and methanol extract of the selected plants were active in the enzyme assays. The extracts of $S$. oleraceus exhibited significant results in proteases assay with $\%$ inhibition $90.2 \pm 1.4, \mathrm{IC}_{50}=23 \pm 1 \mu \mathrm{g}$ (methanol extract) and 71.1 $\pm 1.6, \mathrm{IC}_{50}=45 \pm 2 \mu \mathrm{g}$ (ethyl acetate extract). The solvent extracts of $M$. azedarach and $C$. sinensis showed moderate results in the enzyme inhibition assays. Among all the solvent extracts of the selected plants, hexane and $n$-butanol extracts showed very low response.
\end{abstract}

Key Words: Asteraceae, Meleaceae, Rutaceae, Enzyme inhibition.

\section{INTRODUCTION}

Sonchus oleraceus (Asteraceae) has a variety of medicinal uses including anticancer, antidiarrheal, antinflammatory, cathartic, hydrogogue, lactogogue, digestive purgative, diuretic, emollient and blood purifier. It is also used to stop bleeding, as a mild laxative, abortifacient and as a toothache remedy and cure for opium addiction ${ }^{1}$. Melia azedarach L (Meliaceae) commonly known as Paraiso is used for medicinal, ornamental and timber purposes ${ }^{2}$. Aqueous extract of this plant has shown to possess hypoglycemic and antioxidant properties ${ }^{3,4}$. Different parts of this plant are being used in leprosy, scrofula, anthelmintic, diuretic, antifungal, antimalarial, insecticidal, antiseptic. Citrus sinensis (Rutaceae) is one of the important medicinal plants, being used for the treatment of various ailments such as antidiabetic ${ }^{5}$, antimicrobial ${ }^{6}$, antifungal ${ }^{7}$, hypotensive agent ${ }^{8}$, antioxidant ${ }^{9,10}$, carminative, insect repellent, antibacterial, larvicidal, antiviral, uricosuric, anti-yeast, antihepatotoxic and antimutagenic agent. The leaves and the peel of the fruit have been used to kill mosquito larvae and mites ${ }^{11}$.

Alzheimer's disease, senile dementia, ataxia, myasthenia gravis and Parkinson's diseases are induced by over activity of acetylcholinesterase (AChE). The application of AChE inhibitors is currently the only approved therapy for enhancement of central cholinergic function in patients with Alzheimer's disease ${ }^{12}$. There are a few synthetic medicines, e.g., tacrine, donepezil used for treatment of cognitive dysfunction and memory loss associated with Alzheimer's disease $^{13}$. These compounds are reported to have side effects including gastrointestinal problems ${ }^{14}$. Therefore, the search of more safe and novel compounds with AChE inhibitory activity has become a very important issue. Many pathological disorders are caused by the abnormal regulation of proteolytic enzymes, resulting in tissue destruction or irregular processing of other proteins. Trypsin is a serine protease enzyme that catalyzes the hydrolysis of the peptide bond of protein in the small intestine. In the course of our studies on the enzyme inhibition potential of medicinal plants, the present research work was designed to evaluate AChE and protease inhibitory potential of Sonchus oleraceus, Melia azedarach and Citrus sinensis.

\section{EXPERIMENTAL}

Acetylthiocholine iodide and 5,5'-dithiobis[2-nitrobenzoic acid] (DTNB) were purchased from Sigma (St. Louis, MO, USA) while, erythrocytes (Acetylcholine esterase) obtained from the Biochemistry Lab, Mayo Hospital Lahore. No-benzoyl-DL-arginine-para-nitroanilide hydrochloride (BApNA), trypsin from bovine serum was from Merck. Solvents of analytical grade were purchased from Panerac (Spain). All other chemicals and reagents of analytical grade were from Merck (Germany). 
Collection of plant material: Whole plant of $M$. azedarach $(6.8 \mathrm{~kg})$ and aerial parts of $S$. oleraceus were collected from Muree region Pakistan, while fruit peel of $C$. sinensis were collected from Botanical Garden, GC University, Lahore. The plants were identified at Botany Department, GC University, Lahore and voucher specimens were submitted of each plant at Sultan Herbarium.

Extraction: The plant materials were shade dried, pulverized and extracted in methanol at room temperature. Crude extracts were filtered and concentrated at reduced pressure using rotary evaporator. Crude methanolic extracts were dissolved in water and fractionated with $n$-hexane, ethyl acetate and $n$-butanol successively.

Acetylcholine esterase assay: Acetylcholine esterase inhibitory activity was measured by the spectrophotometric method $^{15,16}$. Acetylthiocholine iodide was used as substrate in the assay. The reaction mixture contained $1.5 \mathrm{~mL}$ of $(100$ $\mathrm{mM}$ ) tris buffer (pH 7.8), 1.0 mL of DTNB, $200 \mu \mathrm{L}(50-250$ $\mu \mathrm{g} / \mathrm{mL}$ ) of test sample solution and $200 \mu \mathrm{L}$ of acetyl cholinesterase solution (erythrocytes), which were mixed and incubated for $15 \mathrm{~min}\left(25^{\circ} \mathrm{C}\right)$. The reaction was initiated by the addition of $200 \mu \mathrm{L}$ acetylthiocholine. The hydrolysis of acetylthiocholine was monitored at $412 \mathrm{~nm}$ after $0.5 \mathrm{~h}$. Hyoscine was used as positive control. All the reactions were performed in triplicate. The percentage inhibition was calculated as follows:

$$
\text { Inhibition }(\%)=\frac{(E-S)}{E} \times 100
$$

where; $\mathrm{E}$ is the activity of the enzyme without test compound and $\mathrm{S}$ is the activity of enzyme with test compound.

Protease inhibition assay: Protease inhibition assay of all extracts was carried out by spectrophotometric method with some modifications ${ }^{17}$. The stock solution of trypsin $(2$ $\mathrm{mg} / \mathrm{mL}$ ) was prepared Tris buffer. N $\alpha$-benzoyl-DL-arginineparanitroanilide hydrochloride (BApNA) was dissolved in DMSO $(20 \mathrm{mg} / \mathrm{mL})$. Enzyme $(0.3 \mathrm{~mL})$ and inhibitor $(0.1 \mathrm{~mL})$ were incubated at $37^{\circ} \mathrm{C}$ for $15 \mathrm{~min}$ followed by addition of $0.6 \mathrm{mM}$ substrate. The reaction mixture was incubated at $37^{\circ} \mathrm{C}$ for $0.5 \mathrm{~h}$. The reaction was quenched by adding $200 \mu \mathrm{L}$ (30\% acetic acid) and the absorbance was measured at 410 nm using UV/VIS spectrophotometer. Phenylmethane sulfonylfluoride (PMSF) was used as positive inhibitor. Trypsin inhibitory potential was calculated by using the following formula:

$$
\text { Inhibition }(\%)=\frac{\text { Absorbance }(\text { blank })-\text { Absorbance }(\text { test })}{\text { Absorbance }(\text { blank })} \times 100
$$

\section{RESULTS AND DISCUSSION}

Alzheimer s disease (AD) is a neurologic disorder resulting in loss of memory. One of the ways to treat Alzheimer's disease is to control the activity of acetylcholine esterase (AChE) through acetylcholine esterase inhibitors (AChEIs). Proteases are essential in the metabolic system to regulate normal physiological functions of cells. A number of diseases like cancer, pulmonary emphysema and arthritus are reported to be induced by over activity of proteases ${ }^{18}$. In our study twelve extracts of three medicinal plants were tested for their AChE and protease inhibitory potential ${ }^{15-17,19}$. The extracts of S. oleraceus remarkably inhibited the activity of trypsin with $\mathrm{IC}_{50}$ values in the range of 23- $45 \mu \mathrm{g}$, in the order of \% inhibition $\mathrm{SoM}>\mathrm{SoE}>$ $\mathrm{SoH}>\mathrm{SoB}$. The results of AChE activitiy in the extracts of $S$. oleraceus revealed highest activity in $\mathrm{SoE}\left(76.7 \pm 2.6 \%\right.$; $\mathrm{IC}_{50}$ $=57 \pm 2$ ), while all other extracts showed moderate activity in the range of $39-53 \%$ inhibition. Previous phytochemical studies on Sonchus species revealed the presence of sesquiterpene glucosides, sesquiterpene lactones glucosides and flavonoids ${ }^{20}$. Our results of phytochemical analysis of $S$. oleraceus also showed the presence of alkaloids in the ethyl acetate extract (SoE). Therefore, significant results of AChE activity in SoE can be attributed to the presence of alkaloids. Among all the extracts of $M$. azedarach, $\mathrm{MaE}\left(\mathrm{IC}_{50}=92 \pm 1\right.$ $\mu \mathrm{g})$ and $\mathrm{MaM}\left(\mathrm{IC}_{50}=120 \pm 3 \mu \mathrm{g}\right)$ showed inhibitory activity above $50 \%$ at $1 \mathrm{mg} / \mathrm{mL}$. MaH and $\mathrm{MaB}$ showed poor results in AChE assay. Protease inhibitory activity of the extracts of M. azedarach were found in the order of $\mathrm{MaE}>\mathrm{MaM}>\mathrm{MaB}$ $>\mathrm{MaH}$. Systematically, M. azedarach is used as an emetic, cathartic, anthelmintic, antipyretic, expectorant and diuretic ${ }^{21}$. Chemical composition of this plant reveals the presence of alkaloids, tannins, phenolic acids and terpenes ${ }^{21}$. Therefore, activity of the extracts (MaM and $\mathrm{MaE}$ ) can be attributed to the synergistic effect of these compounds. The solvent extracts of $C$. sinensis showed moderate results in AChE assay in CsM and $\mathrm{CsE}(44.3 \pm 1.3$ and $53.2 \pm 1.4 \%$ inhibition respectively), while the extracts in hexane and butanol were found inactive. CsE of $C$. sinensis was the most active extract in the protease assay, with $\mathrm{IC}_{50}=87 \pm 1 \mu \mathrm{g}$ followed by methanol extract $\mathrm{CsM}\left(\mathrm{IC}_{50}=113 \pm 1 \mu \mathrm{g}\right.$ ), while $\mathrm{CsH}$ and $\mathrm{CsB}$ did not show positive results (Table-1 and Fig. 1). The peel of citrus fruit is a rich source of bioactive compounds such as flavanones and many polymethoxylated flavones, which are rare in other plants $^{22}$. Therefore, these compounds may be responsible for $\mathrm{AChE}$ and protease inhibition activity of the solvent extracts of $C$. sinensis in our studies.

TABLE-1

AChE AND PROTEASE INHIBITION ACTIVITY OF THE EXTRACTS OF $S$. oleraceus, $M$. azedarach AND C. sinensis

\begin{tabular}{lcccc}
\hline $\begin{array}{c}\text { Extracts } \\
(1 \mathrm{mg} / \mathrm{mL})\end{array}$ & $\begin{array}{c}\text { AChE } \\
\text { inhibition } \\
(\%)\end{array}$ & $\begin{array}{c}\mathrm{IC}_{50} \\
(\mu \mathrm{g})\end{array}$ & $\begin{array}{c}\text { Protease } \\
\text { inhibition } \\
(\%)\end{array}$ & $\begin{array}{c}\mathrm{IC}_{50} \\
(\mu \mathrm{g})\end{array}$ \\
\hline S. oleraceus & & & & \\
$\mathrm{SoM}$ & $53.1 \pm 1.9$ & $93 \pm 1$ & $90.2 \pm 1.4$ & $23 \pm 1$ \\
$\mathrm{SoH}$ & $47.1 \pm 1.8$ & - & $48.1 \pm 1.2$ & - \\
$\mathrm{SoE}$ & $76.7 \pm 2.6$ & $57 \pm 2$ & $71.1 \pm 1.6$ & $45 \pm 2$ \\
$\mathrm{SoB}$ & $39.3 \pm 1.2$ & - & $11.6 \pm 2.2$ & - \\
\hline M. azedarach & & & & \\
$\mathrm{MaM}$ & $58.3 \pm 1.6$ & $120 \pm 3$ & $41.2 \pm 2.5$ & - \\
$\mathrm{MaH}$ & $1.2 \pm 2.2$ & - & $5.4 \pm 2.2$ & - \\
$\mathrm{MaE}$ & $69.1 \pm 1.9$ & $92 \pm 1$ & $58.6 \pm 2.8$ & $150 \pm 2$ \\
$\mathrm{MaB}$ & $11.6 \pm 1.2$ & - & $25.1 \pm 2.6$ & - \\
\hline C. sinensis & & & & \\
$\mathrm{CsM}$ & $44.3 \pm 1.3$ & - & $58.8 \pm 1.8$ & $113 \pm 1$ \\
$\mathrm{CsH}$ & $0.0 \pm 0.0$ & - & $0.0 \pm 0.0$ & - \\
$\mathrm{CsE}$ & $53.2 \pm 1.4$ & $98 \pm 2$ & $64.1 \pm 2.3$ & $87 \pm 1$ \\
$\mathrm{CsB}$ & $1.3 \pm 2.2$ & - & $31.3 \pm 1.8$ & - \\
\hline
\end{tabular}




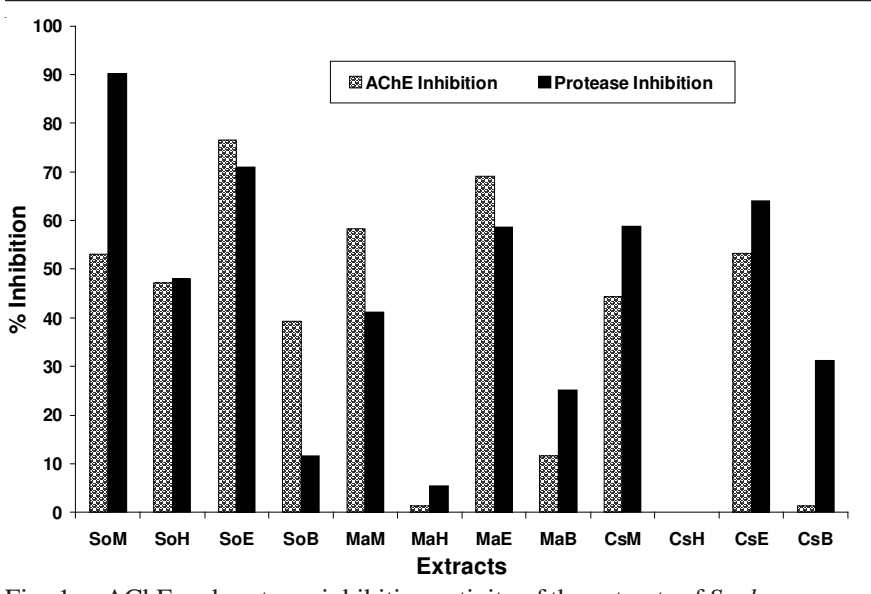

Fig. 1. AChE and protease inhibition activity of the extracts of S. oleraceus, $M$. azedarach and $C$. sinensis

\section{Conclusion}

In the present study, solvent extracts of $S$. oleraceus, $M$. azedarach and $C$. sinensis were analyzed for their acetylcholine esterase and protease inhibition potential. Our findings suggest that the polar solvent extracts of these plants have potential to be used in the cure of diseases associated with the excessive activity of proteases and AChE. Further studies towards isolation and purification of active principles from these plants are in progress in our laboratory.

\section{REFERENCES}

1. O.J. Florence, A.A. Adeolu and J.A. Anthony, Rec. Nat. Prod., 5, 29 (2011).

2. C.C. Mariäa, M.G. Laura, G.F. Carlos and M.P. Sara, J. Agric. Food Chem., 51, 2506 (2003).
3. P. Chaturvedi and M. Segale, Scient. Res. Essays, 2, 508 (2007).

4. D. Shahwar, M.A. Raza, T. Ali and V.U. Ahmad, J. Chem. Soc. Pak., 33, 715 (2011).

5. S.P. Hamendra and K. Anand, Bio Factors, 31, 17 (2007).

6. D.R. Caccioni, M. Guizzardi, D.M. Biondi, A. Renda and G. Ruberto, Int. J. Food Microb., 43, 73 (1998).

7. R.R.J. Stange, S.L. Midland, J.W. Eckert and J.J. Sims, J. Nat. Prod., 56, 1637 (1993).

8. H. Kumamoto, Y. Matsubara, Y. Iizuka, K. Okamoto and K. Yokoi, Agric. Biol. Chem., 50, 781 (1986).

9. A.R. Proteggente, A. Saija, A. De-Pasquale and C.A. Rice-Evans, Free Radic. Res., 37, 681 (2003).

10. F.L. Kanaze, A. Termentzi, C. Gabrieli, I. Niopas, M. Georgarakis and E. Kokkalou, Biomed. Chromatogr., 23, 239 (2008).

11. G.L. Mwaiko, East African Med. J., 69, 223 (1992).

12. J.M. Rollinger, J. Ewelt, C. Seger, S. Sturm, E.P. Ellmerer and H. Stuppner, Planta Med., 71, 1040 (2005).

13. M.H. Oh, P.J. Houghton, W.K. Whang and J.H. Cho, Phytomedicine, 11, 544 (2004).

14. V. Schulz, Phytomedicine, 10, 74 (2003).

15. D. Shahwar, S. Rehman and M.A. Raza, J. Med. Plants Res., 4, 260 (2010).

16. D. Shahwar, Shafiq-Ur-Rehman, M.A. Raza and K. Tania, Asian J. Chem., 23, 1783 (2011).

17. D. Shahwar, M.A. Raza, Shafiq-Ur-Rehman, M.A. Abbasi and AttaUr-Rahman, Nat. Prod. Res., 26, 1087 (2012).

18. D. Shahwar, S. Ullah, M.A. Raza, U. Sana, A. Yasmeen, S. Ghafoor and N. Ahmad, J. Med. Plants Res., 5, 7011 (2011).

19. A. Giovanni and P.F. David, Med. Chem. (Shariqah (United Arab Emirates), 1, 71 (2005).

20. X. Yang-Jun, S. Sun, L. Sun, D. Qiu, X. Liu and Z. Jiang, Food Chem., 111, 92 (2008).

21. S.R. Baquar, Medicinal and Poisonous Plants of Pakistan, Printas, Karachi, Pakistan, pp. 279 (1989).

22. M.M. Ahmad, Salim-ur-Rehman, Z. Iqbal, F.M. Anjum and J.I. Sultan, Pak. J. Bot., 38, 319 (2006). 